\title{
Cardiovascular and Respiratory Responses to Right Atrial Injections of Phenyl Diguanide in Pentobarbital-Anesthetized Newborn Piglets
}

\author{
MARGO SCHLEMAN, NORMAN GOOTMAN, AND PHYLLIS M. GOOTMAN \\ WITH THE TECHNICAL ASSISTANCE OF LINDA A. CRANE AND BARBARA J. BUCKLEY
}

Department of Pediatrics, Long Island Jewish-Hillside Medical Center, State University of New York at Stony Brook, Health Sciences Center, New Hyde Park, New York and Department of Physiology, Downstate Medical Center, State University of New York, Brooklyn, New York, USA

\begin{abstract}
Summary
The present series of experiments was designed to determine whether the piglet has mature cardiorespiratory responses to the administration of phenyl diguanide (PDG) similar to those reported in adult mammals. A total of 26 acutely instrumented piglets aged 2-23 days were lightly anesthetized with sodium pentobarbital. After control conditions were established, PDG was injected into the right atrium. Each animal was its own control for determination of presence and magnitude of aortic pressure, heart rate, respiratory rate and volume, and blood flow responses to test doses of PDG. A fall in blood pressure was observed in all animals within 2-4 sec after right atrial injection of PDG. Bradycardia occurred and a transient cardiac arrhythmia, consisting of 2 nd and 3rd degree heart block, was observed in most animals; the latter has not been previously reported. Apnea followed by rapid shallow breathing was observed in most animals. This respiratory effect was more pronounced in the younger animals. After atropine, PDG elicited a monophasic rise in aortic pressure; the cardiac rhythm and rate changes were abolished. However, the apneic response was retained. Subsequent bilateral vagotomy abolished the hypotensive effect on PDG. Such results suggest the possibility that the piglet's cardiorespiratory response to the administration of PDG may be evoked by stimulation of type $J$ pulmonary receptors. These have been postulated to be responsible for the triad of responses of hypotension, bradycardia, and apnea seen in other species after PDG administration.
\end{abstract}

\section{Speculation}

At present, there is no explanation for the apnea and bradycardia observed in premature infants with Respiratory Distress Syndrome and/or a large patent ductus arteriosus. Mild interstitial pulmonary edema has been postulated to be the physiologic stimulus for the type $\mathbf{J}$ (juxtacapillary) pulmonary receptor. The authors speculate that the piglet's response to PDG which includes apnea, hypotension, and bradycardia may be mediated by artificial stimulation of the $J$ receptor. It is possible that in the human neonate, an immaturely controlled or an inappropriately strong response to the pathophysiologic stimulation of pulmonary edema may be a mechanism for the clinical symptoms of apnea and bradycardia in the small neonate.

Apnea has been shown to occur in adult animals when pulmonary receptors of various types are stimulated $(1,3,5,6,12,14$, $16-18,20)$. Type $\mathrm{J}$ receptors that are juxtacapillary in location (10, 15-18) have been studied in the cat and dog using pharmacologic stimuli such as phenyl diguanide, capsaicin, or histamine. The somatic and visceral responses attributed to stimulation of the $J$ receptors are hypotension, bradycardia, and respiratory inhibition followed by rapid, shallow breathing $(1,16-18,20)$. Work by Kalia (13) in the kitten, showed that there is a developmental delay for the full expression of the cardiorespiratory response to $\mathbf{J}$ receptor stimulation with phenyl diguanide. No other work in young animals has been published. The piglet has been shown in this laboratory to develop certain central vasomotor control mechanisms postnatally $(2,9)$. The present series of experiments was designed to determine whether cardiorespiratory responses to phenyl diguanide are present in the neonatal pig. The current results indicate that a reflex resembling that similar to $\mathrm{J}$ receptor activation is present in the newborn piglet.

\section{MATERIALS AND METHODS}

A total of 28 piglets, age 2-23 days were studied. Anesthesia was induced in 26 piglets using $1 \%$ halothane in a mixture of $50 \%$ $\mathrm{N}_{2} \mathrm{O}$ and $50 \% \mathrm{O}_{2}$ to permit surgical anesthesia for the placement of catheters, flow probes and tracheostomy tube. These animals were then maintained on sodium pentobarbital as needed $(5 \mathrm{mg}$ / $\mathrm{kg}$ ). These animals spontaneously breathed a mixture of $50 \% \mathrm{~N}_{2} \mathrm{O}$ and $50 \% \quad \mathrm{O}_{2}$ via a tracheostomy tube. As a test that neither halothane or $\mathrm{N}_{2} \mathrm{O}$ was sensitizing the receptors producing the responses reported in this paper, the other two piglets, aged 2 days and 1 week, were controls. These animals were anesthetized only with sodium pentobarbital and breathed just room air. In all animals, a Harvard small animal respirator, model 1665, was available for use during periods of prolonged apnea and could be quickly attached to the tracheostomy tube. The arterial blood pressure was measured with a calibrated Statham P23Db transducer attached to an indwelling catheter in the femoral artery. Iv dextrose and saline was continuously infused through a catheter in the left jugular vein. Blood flow through the carotid and femoral arteries was measured with calibrated Biotronex electromagnetic flow probes, as in our previous studies $(2,4,19)$. Intraesophageal pressure was measured by a Statham P23BB transducer attached to a catheter whose tip was located in the intrathoracic portion of the esophagus. End-tidal $\mathrm{CO}_{2}$ was measured with a Beckman rapid infrared gas analyzer. Phasic changes were recorded and used to determine respiratory rate. A continuous recording of all the above variables, together with lead II of the ECG, was made on a Beckman penwriter. Arterial blood gases and $\mathrm{pH}$ were monitored frequently with a Radiometer microanalyzer and body temperature was maintained by a warming pad and an overhead heater as in our previous studies $(2,4,19)$.

After control conditions were established, PDG (supplied by Drs. M. Kalia and A. S. Paintal) was injected into the right atrium in doses of $80 \mu \mathrm{g} / \mathrm{kg}$. This dose was chosen after preliminary dose response trials in eight animals demonstrated that this dose elicited 
a full cardiorespiratory response. The drug was instilled in a premeasured length of iv tubing and then flushed through with saline to clear the catheter. Injections of similar volumes of saline were made into the right atrium as controls for the responses observed with the drug (20). In 15 animals, including the two controls, PDG was also injected into the descending aorta and into a carotid artery, in order to examine the possibility of receptors in other locations $(1,7,16)$. In some animals, including the 2 day-old control, PDG was administered after blockade with atropine $(0.4 \mathrm{mg} / \mathrm{kg})$ of the muscarinic cholinergic receptors of the parasympathetic system and then after vagotomy (20 animals). At the end of all experiments, the animals were killed and examined for placement of catheters and for the presence of a patent foramen ovale.

Each animal was its own control for determination of presence and magnitude of aortic pressure, heart rate, and blood flow responses to test doses of PDG. Responses were expressed both as absolute change and as percent change, and treated statistically as in previous work $(2,9)$. The statistical significance of observed changes was determined, and age-related differences in observed changes were compared among four subgroups of animals (aged 2-4 days, 1 wk, 2 wk, and $3 \mathrm{wk}$ ) by the paired sample $t$ test. The null hypothesis was rejected at $P \leq 0.05$.

\section{RESULTS}

The control values given in Table 1 are within the range of those previously reported for other piglets studied in our laboratories $(2,4,9,19)$. Table 2 summarizes the cardiorespiratory effects of a single injection of $80 \mu \mathrm{g} / \mathrm{kg}$ of PDG in each age group of piglets. Such responses were generally reproducible in each animal.

A fall in blood pressure was observed within $2 \mathrm{sec}$ in all animals up to and including 2 wk of age, and within $4 \mathrm{sec}$ in 3 wk-old, after the right atrial injection of PDG. There were two patterns of response. In the first, there was only a fall in pressure, as illustrated in Figure 1. In the second, there was an initial fall followed by a secondary rise, as illustrated in Figure 2. This latter response predominated in animals up to $1 \mathrm{wk}$ of age, and was not seen in any of the oldest ones.

Bradycardia occurred after PDG injection (see Table 2). There was no apparent relationship between the magnitude of response to PDG and the resting heart rate. A transient cardiac arrhythmia, consisting of 2 nd and 3rd degree heart block was observed in most animals. This was most clearly seen when the recording speed was increased and the $p$ waves were easier to identify (see Fig. 3).

The apnea after PDG administration, shown in Figures 1-3, was characterized by forceful prolonged expiration that lasted several sec. The duration of the apnea was longest in the youngest animals (see Table 2). After the apneic period, the pattern of respiration varied in animals up to $1 \mathrm{wk}$ old, but an increase in rate predominated in older animals (see Table 2 ). Several min after PDG administration, spontaneous apnea occurred in eight animals of differing ages, in whom no such episodes had occurred before injection of PDG. Neither hypotension, bradycardia, nor cardiac arrhythmia accompanied these late apneic periods. There was no apparent correlation with body temperature or arterial blood gas composition and $\mathrm{pH}$.

No consistant changes in femoral or carotid flows and resistances accompanied the cardiorespiratory effects of PDG.

Control injections of PDG into the carotid artery and/or descending aorta resulted in blood pressure responses with variable direction which had longer latencies $(6-10 \mathrm{sec})$ and were unaccompanied by apnea. After atropine, PDG elicited a monophasic rise in aortic pressure in 10 of 15 animals tested, including the youngest control. The heart rate response was abolished while the respiratory responses were retained. After vagotomy, however, there were no responses in 11 animals (including the youngest control), falls

Table 1. Control conditions at onset of test series of $P D G$ injections in piglets ${ }^{1}$

\begin{tabular}{|c|c|c|c|c|}
\hline & \multicolumn{4}{|c|}{ Age of Piglets } \\
\hline & $2-4$ days $(N=6)$ & $1 \mathrm{wk}(\mathrm{N}=7)$ & 2 wk $(N=9)$ & 3 wk $(\mathrm{N}=4)$ \\
\hline Body wt $(\mathrm{kg})$ & $1.3 \pm 0.2$ & $1.3 \pm 0.2$ & $2.4 \pm 0.3$ & $2.7 \pm 0.5$ \\
\hline Mean AoP (mm Hg) & $57.3 \pm 3.3$ & $69.9 \pm 6.4$ & $74.3 \pm 5.4$ & $84.3 \pm 11.0$ \\
\hline Heart rate $(\mathrm{bpm})$ & $175 \pm 9.2$ & $160 \pm 9.1$ & $166 \pm 9.5$ & $137 \pm 15.4$ \\
\hline Respiration rate & $36 \pm 8.1$ & $37 \pm 2.8$ & $36 \pm 6.8$ & $25 \pm 2.9$ \\
\hline $\begin{array}{l}\text { Arterial } \mathrm{pO}_{2} \text { (torr) } \\
\qquad\left(\mathrm{FiO}_{2}=0.5\right)\end{array}$ & $147 \pm 22.9$ & $149 \pm 14.8$ & $129 \pm 23.0$ & $181 \pm 29.6$ \\
\hline Arterial $\mathrm{pCO}_{2}$ (torr) & $30.8 \pm 2.9$ & $35.4 \pm 1.9$ & $33.4 \pm 1.5$ & $38.5 \pm 4.1$ \\
\hline Arterial $\mathrm{pH}$ & $7.38 \pm 0.05$ & $7.39 \pm 0.03$ & $7.42 \pm 0.03$ & $7.37 \pm 0.03$ \\
\hline
\end{tabular}

${ }^{1}$ Mean values and their standard errors.

Table 2. Effects of single doses of $75-80 \mu \mathrm{g} P D G / \mathrm{kg}$ in piglets ${ }^{1}$

\begin{tabular}{|c|c|c|c|c|}
\hline & \multicolumn{4}{|c|}{ Age of piglets } \\
\hline & $2-4$ days $(N=5)$ & $1 \mathrm{wk}(\mathrm{N}=5)$ & 2 wk $(N=6)$ & 3 wk $(N=4)$ \\
\hline \multicolumn{5}{|l|}{ Change in $\overline{\mathrm{AoP}}$} \\
\hline $\begin{array}{l}\text { Absolute (mm Hg) } \\
\text { Percent }\end{array}$ & $-20.2 \pm 2.7^{2}$ & $-12.8 \pm 2.6^{2}$ & $-28.2 \pm 5.0^{2}$ & $-30.0 \pm 9.9^{2}$ \\
\hline Percent & $-37.2 \pm 6.3$ & $-18.4 \pm 3.8$ & $-37.8 \pm 8.0$ & $-36.5 \pm 9.6$ \\
\hline \multicolumn{5}{|l|}{ Change in heart rate } \\
\hline $\begin{array}{l}\text { Absolute (bpm) } \\
\text { Percent }\end{array}$ & $-25 \pm 9.2^{2}$ & $-28 \pm 11.6^{2}$ & $-50 \pm 21.2$ & $-28 \pm 11.7$ \\
\hline Percent & $-17 \pm 7.3$ & $-22 \pm 9.7$ & $-29 \pm 11.8$ & $-17 \pm 5.7$ \\
\hline Heart block incidence $(\%)$ & 60 & 60 & 83 & 50 \\
\hline Apnea incidence (\%) & 100 & 100 & 100 & 50 \\
\hline Apnea duration (sec) & $10.2 \pm 3.9$ & $7.2 \pm 2.1$ & $5.8 \pm 2.4$ & $1.0 \pm 1.0$ \\
\hline \multicolumn{5}{|c|}{$\begin{array}{l}\text { Apnea duration (sec) } \\
\text { Post apnea change in respiration rate }\end{array}$} \\
\hline $\begin{array}{l}\text { Absolute (pm) } \\
\text { Percent }\end{array}$ & $+10.3 \pm 6.1$ & $+7.4 \pm 8.4$ & $+6.4 \pm 1.3^{2}$ & $+8.4 \pm 1.7^{2}$ \\
\hline Percent & $+32.8 \pm 12.8$ & $+20.4 \pm 21.2$ & $+22.1 \pm 6.7$ & $+29.0 \pm 2.3$ \\
\hline
\end{tabular}

1 Mean values and their standard errors, except for incidence of heart block and apnea.

${ }^{2}$ Significantly different from zero change $(0.002<P<0.05)$. Only absolute changes were subjected to statistical testing. 


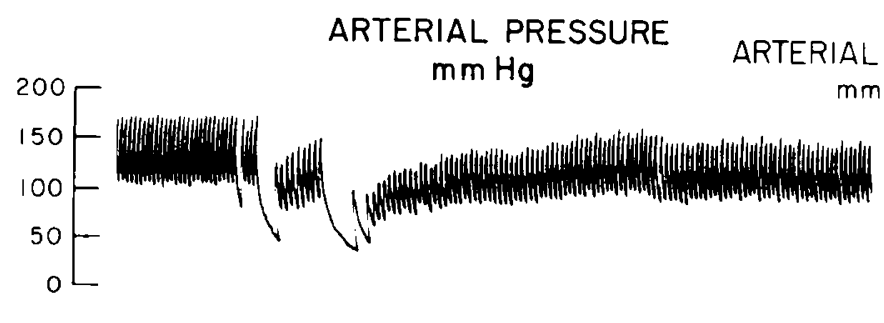

EKG $\quad E K G$

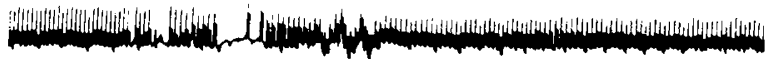

INSPIRATION $\uparrow$

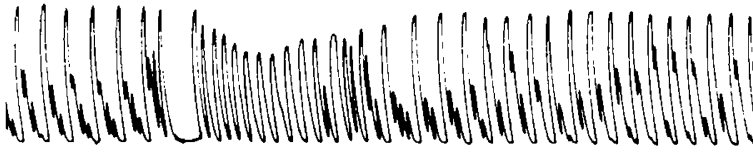

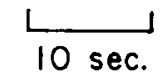

INSPIRATION $\uparrow$

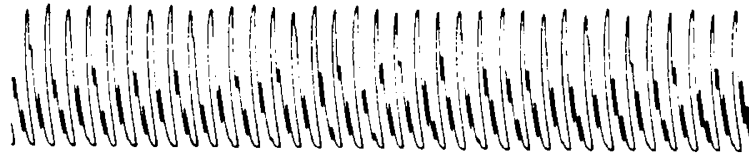

Fig. 1. Responses to PDG $(80 \mu \mathrm{g} / \mathrm{kg})$ in an 18-day-old piglet.

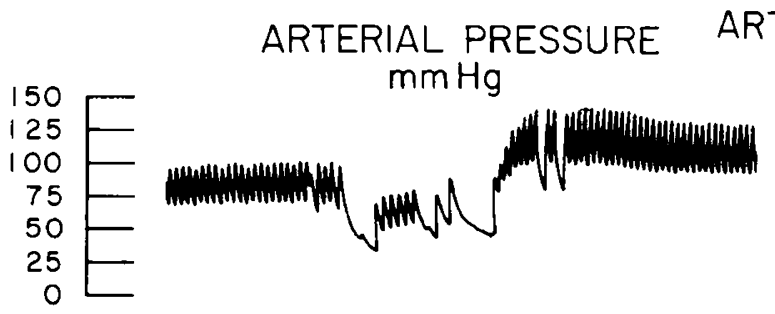

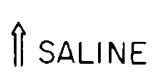

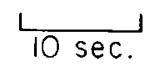

EKG

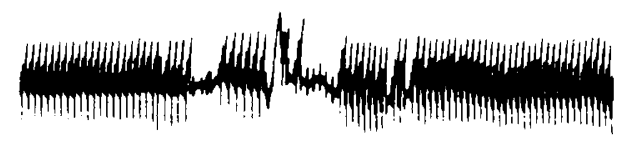
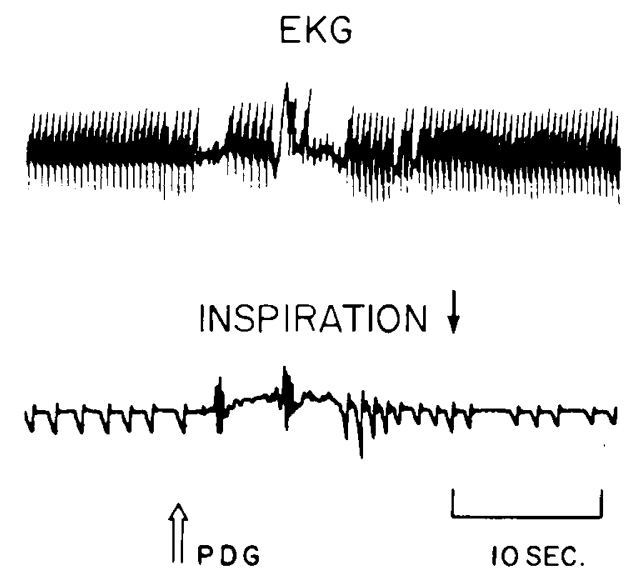

INSPIRATION

EKG
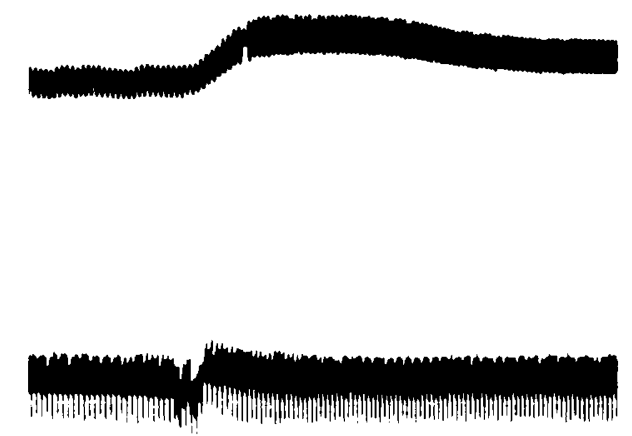

$\mathrm{mm} \mathrm{Hg}$
$\mathrm{mmESURE}$

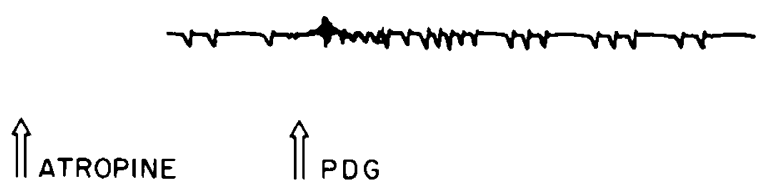

Fig. 2. Responses to PDG $(80 \mu \mathrm{g} / \mathrm{kg})$ in a 7 -day-old piglet.

in pressure in 6, and biphasic blood pressure changes (fall, rise) in 4. These responses had longer latencies $(8-20 \mathrm{sec})$ and were not accompanied by respiratory changes.

There were no differences in responses obtained in the two controls and the other 26 halothane-induced animals.

\section{DISCUSSION}

These results demonstrate that the piglet's response to PDG is somewhat similar to that of the adult cat to $\operatorname{PDG}(5,6,12,16-18)$ and the response of the adult dog to capsaicin $(3,12,16)$. It has been shown that both these drugs stimulate type $J$ pulmonary receptors. The piglet's response to PDG may also be mediated by type $\mathrm{J}$ pulmonary receptors. It has been reported in the kitten that there is a slow development of the response to PDG (13). Other studies also indicate that cardiovascular function and control is relatively immature in the kitten at birth (11). This is in contrast to the piglet which demonstrates a full cardiorespiratory response by the second day after birth.

Although hypotension was observed in all age groups of piglets, biphasic aortic pressure responses were seen in the younger animals. Because a patent foramen ovale was present in these piglets into the 2 nd postnatal wk, right-to-left shunting with early arrival of PDG into the cerebral circulation might be responsible for these observations. Another possibility is that a delayed overshoot after an initial fall in arterial pressure in younger animals is a 


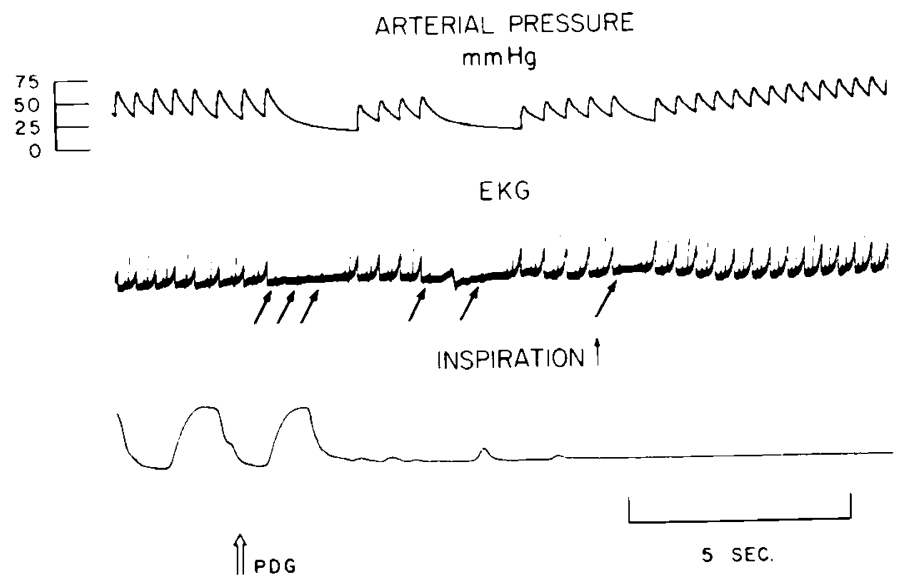

Fig. 3. Effects of a single intraatrial dose of $77 \mu \mathrm{g} \mathrm{PDG} / \mathrm{kg}$ in a 7 -dayold piglet. Original recordings at slow speed to emphasize nature of arrhythmia and of apnea. Arrows indicate $\mathrm{p}$ waves.

consequence of their less developed control mechanisms for blood pressure regulation $(2,9)$.

The bradycardia after PDG injection could be prevented by atropinization and, therefore, is secondary to reflex efferent vagal discharge. However, the observed heart block, also abolished by muscarinic cholinergic blockade, is a finding which was not previously reported in the literature on PDG effects. The lower incidence of heart block in the older animals suggests the possibility that the reflex vagal activation may be modulated in animals in which the sympathetic innervation to the heart is more mature.

The decrease in both the incidence and duration of apnea in the oldest piglets (see Table 2) may be related to a requirement for a larger dose with increasing age. When $130 \mu \mathrm{g} / \mathrm{kg}$ of PDG were injected into the right atrium in two older animals, there was an apnea of longer duration and shorter latency of cardiorespiratory responses.

The persistence of PDG-induced apnea after atropine, but not afte bilateral vagotomy implies that vagal afferents were necessary in the production of this response to PDG. Such results strengthen the possibility that the cardiovascular responses to administration of PDG in piglets may have been evoked by stimulation of receptors similar to those defined as type $J$ receptors in cats and dogs. PDG injection into the carotid artery caused a cardiovascular response of longer latency and was not accompanied by respiratory changes. PDG injection into the descending aorta did not cause any cardiorespiratory response. The occurrence of cardiovascular responses of longer latency unaccompanied by any respiratory changes after PDG injection into the carotid artery or descending aorta also raises the possibility that other receptors in the periphery could be stimulated by PDG as seen in the adult of other species (16).
These results show the functional presence in the piglet of receptors that produce the cardiorespiratory responses similar to those elicited by type $\mathbf{J}$ receptors of other mammalian species.

\section{REFERENCES AND NOTES}

1. Ahluwalia, J. M. Langhorst, P., Krienke, B., and Koepchen, H. P.: Nucleus of the solitary tract and the J reflex. Pflugers Arch., 368: 157 (1977).

2. Buckley, N. M., Gootman, P. M., Gootman, N., Reddy, G. D., Weaver, L. C., and Crane, L. A.: Age-dependent cardiovascular effects of afferent stimulation in neonatal pigs. Biol. Neonate, 30: 268 (1976)

3. Coleridge, H. N., Coleridge, J. C. G., and Kidd, C.: Role of the pulmonary arterial baroreceptors in the effects produced by capsaicin in the dog. $J$. Physiol., 170: 272 (1964).

4. Crane, L. A., Gootman, N., and Gootman, P. M.: Age-dependent cardiovascular effects of halothane anesthesia in neonatal pigs. Arch. Int. Pharmacodyn., 214: 180 (1975).

5. Dawes, G. S., and Mott, J. C.: Circulatory and respiratory reflexes caused by aromatic guanidines. Br. J. Pharmac. Chemother., 5: 65 (1950).

6. Dawes, G. S. Mott, J. C., and Widdicombe, J. G.: Respiratory and cardiovascular reflexes from the heart and lungs. J. Physiol., 115: 258 (1951).

7. Deshpande, S. S., and Devanandan, M. S.: Reflex inhibition of monosynaptic reflexes by stimulation of type J pulmonary endings. J. Physiol., 206: 345 (1970).

8. Gootman, N. Gootman, P. M., Buckley, N. M., Cohen. M. I., Levine M., and Spielberg, R.: Central vasomotor regulation in the newborn piglet (Sus. Scrofa). Am. J. Physiol., 222: 994 (1972).

9. Gootman, P. M., Buckley, N. M., and Gootman, N.: Postnatal maturation of the central neural cardiovascular regulatory system. In: L. D. Longo and D. D Reneau: Fetal and Newborn Cardiovascular Physiology, Vol. I Developmental Aspects, pp. 93-152 (New York, 1978).

10. Hung. K. S., Hertweck, M. S., Hardy, J. D., and Loosli, C. G.: Innervation of pulmonary alveoli of the mouse lung. An electron-microscopic study. Am. J. Anat., 135: 477 (1972).

11. Hutchinson. E. A., Percival, C. J., and Young. I. N.: Development of cardiovascular responses in the kitten. Q. J. Exp. Physiol.. 47: 201 (1962).

12. Kalia, M.: Effects of certain cerebral lesions on the J reflex. Pflugers Arch., 343: 297 (1973).

13. Kalia, $\mathbf{M}$.: Visceral and somatic reflexes produced by $\mathbf{J}$ pulmonary receptors in newborn kittens. J. Appl. Physiol, 41: 1 (1976).

14. Karczewski. W., and Widdicombe, J. G.: The role of the vagus nerves in the respiratory and circulatory responses to intravenous histamine and phenyl diguanide in rabbit. J. Physiol., 201: 271 (1969)

15. Meyrick. B., and Reid. L.: Nerves in rat intraacinar alveoli. An electron microscopic study. Respiratory Physiol., 11: 367 (1971).

16. Paintal, A. S.: Effect of drugs on chemoreceptors, pulmonary and cardiovascular receptors. Pharmac. Ther. B, 3: 41 (1977).

17. Paintal. A. S.: Mechanisms of stimulation of type $\mathbf{J}$ pulmonary receptors. $\mathbf{J}$. Physiol., 203: 511 (1969)

18. Paintal, A. S.: The mechanism of excitation of type $J$ receptors, and the $J$ reflex. In: R. Porter: Breathing: Ciba Foundation Hering-Breuer Centenary Symposium. pp. 59-71 (Churchill, London 1970).

19. Reddy G. D., Gootman, N., Buckley, N. M., Gootman, P. M., and Crane, L.: Regional blood flow changes in neonatal pigs in response to hypercapnia, Hemorrhage and sciatic nerve stimulation. Biol. Neonate, 25: 249 (1974).

20. Shepherd, J. T.: Intrathoracic baroreflexes (review). Mayo Clin. Proc., 48: 426 (1973).

21. The present address of Margo Schleman: Assistant Professor of Pediatrics, Division of Pediatric Cardiology. St. Christopher's Hospital for Children, Philadelphia. Pa. 19133, USA.

22. This research was supported in part, by the Rozenberg-Toner Heart Foundation

23. Requests for reprints should be addressed to: Norman Gootman, M. D.. Director. Division of Pediatric Cardiology, Department of Pediatrics, Long Island Jewish-Hillside Medical Center, New Hyde Park, New York 11040. USA

24. Received for publication March 28, 1978.

25. Accepted for publication October 24, 1978 